\title{
Orthogonal Optimization of Polysaccharide Extraction from Millet Bran
}

\author{
Songling Cai ${ }^{*}$, Min Pang \\ Department of Food Quality and Safety, College of Management, Shanghai Sanda University, Shanghai
}

\begin{abstract}
This paper investigated the effects of liquid-solid ratio, extraction time, extraction temperature and alkali concentration on the extraction rate of millet bran polysaccharides by the enzymatic hydrolysis and alkaline extraction method, then the L9 (34) orthogonal test was designed to optimize the extraction process according to the single factor experiment.The optimum parameters were obtained as follow: 15:1 liquid-solid ratio, five hours extraction time, $80^{\circ} \mathrm{C}$ extraction temperature, and $0.7 \mathrm{~mol} / 1$ concentration of sodium hydroxide. The extraction rate of millet bran polysaccharide reached $11.46 \%$ through the verification experiments under these conditions, and the RSD was $1.79 \%$. Therefore, it can provide some experimental basis for the scientific research of millet bran polysaccharides in the future.
\end{abstract}

\section{Introduction}

Millet is a traditional Chinese grain, also known as Sumi, annual grass family genus. Millet originated from the Yellow River Valley in China, and is one of the main food crops widely planted in northern China[1]. Millet is rich in nutrients with appropriate proportion, mainly including carbohydrates, proteins, vitamins, minerals, etc.As a good source of food nutrition, it has the certain health care function and medicinal value[2].

Millet bran is a by-product of millet processing rich in various nutrients. It consists of pericarp, seed coat, aleurone layer, a small amount of embryo and endosperm.Cellulose accounts for more than $18 \%$ of the total bran. It is an ideal source of edible cellulose[3].Cereal fiber can not only promote intestinal peristalsis and prevent constipation, but also has physiological functions such as anti-cancer, lowering blood lipid, regulating blood sugar levels and preventing obesity. However, there are more studies on wheat dietary fiber, oat dietary fiber, barley dietary fiber and rice bran dietary fiber at home and abroad while research based on Millet bran dietary fiber is rare, especially water-insoluble dietary fiber.

Studies[4-7] at home and abroad show that the physiological function of dietary fiber is closely related to its polysaccharide components. Therefore, in this study, millet bran was enzymatically hydrolyzed, and then crude polysaccharides(dietary fiber polysaccharides) were extracted by alkali method. The effects of liquidsolid ratio, extraction time, extraction temperature and alkali concentration on the extraction rate of millet bran polysaccharides were analyzed. According to the single factor experimental results, L9 (34) orthogonal test was designed to optimize the extraction process of polysaccharide from millet bran.

\section{Materials and instruments}

\subsection{Reagents}

heat-stable $\alpha$-amylase(Sigma-A3306), papain (BR Shanghai Sinopharm Reagent), glucoamylase (Wokai $10^{5} \mu / \mathrm{ml}$ ), sodium hydroxide(Shanghai Sinopharm Reagent), absolute ethanol(Shanghai Sinopharm Reagent), glucose(Shanghai Sinopharm Reagent), concentrated sulfuric acid(Shanghai Sinopharm Reagent), phenol(Shanghai Sinopharm Reagent), hydrochloric acid (Shanghai Sinopharm Reagent).

\subsection{Instruments}

rice huller (Sinograin), mill(Bear FSJ-A05B1), magnetic stirrer(S78-1), acidity meter(Leici PHS-3C), electrothermal constant temperature flume(Senxin DK450B), biserial six hole water-bath(Senxin DK-S26), electronic balance(Mettler Toledo AL104), ultraviolet spectrophotometer(Xinmao 752W), centrifuge(Anting GL-12B), pipette gun(eppendorf $0-50 \mu \mathrm{L} 、 20-200 \mu \mathrm{L}$ 、 $0-1000 \mu \mathrm{L} 、 0-5000 \mu \mathrm{L})$, etc.

\section{Methods}

\section{1 drawing standard curve}

\subsubsection{5\% phenol solution preparation}

Dilute by $80 \%$ phenol(weighing 160 grams of analytical pure phenol and 40 grams of water to dissolve), which

\footnotetext{
* Corresponding author: caisongling598@,126.com
} 
can be stored in the dark refrigerator for a long time. Each determination used it right after it was ready.

\subsubsection{The preparation of standard glucose solution}

Weigh $0.5000 \mathrm{~g}$ glucose of constant weight dried at $105^{\circ} \mathrm{C}$, add distilled water to dissolve to $500 \mathrm{ml}(1 \mathrm{mg} / \mathrm{ml}$ reserve solution ), then accurately absorb $10 \mathrm{ml}$ of this reserve solution diluted to $100 \mathrm{ml}$. The standard glucose solution of $0.1 \mathrm{mg} / \mathrm{ml}$ obtained.

\subsubsection{Drawing the glucose standard curve}

Absorb $0.1 \mathrm{mg} / \mathrm{ml}$ glucose standard solution 0, 2.5, 5.0, $7.5,10.0,12.5 \mathrm{ml}$ to $25 \mathrm{ml}$ volumetric flask respectively, add distilled water to the scale, then shake well to be measured. Pipet $2 \mathrm{ml}$ the above glucose solution of different concentrations into graduated test tube, add 1

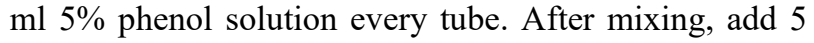
$\mathrm{ml}$ sulfuric acid. The absorbance was measured at $490 \mathrm{~nm}$ after the chromogenic reaction for half-hour. The regression equation was calculated as below: $\mathrm{Y}=0.0127 \mathrm{X}+0.0038, \mathrm{R}^{2}=0.9999$, showing a good linear relationship (Fig.1).

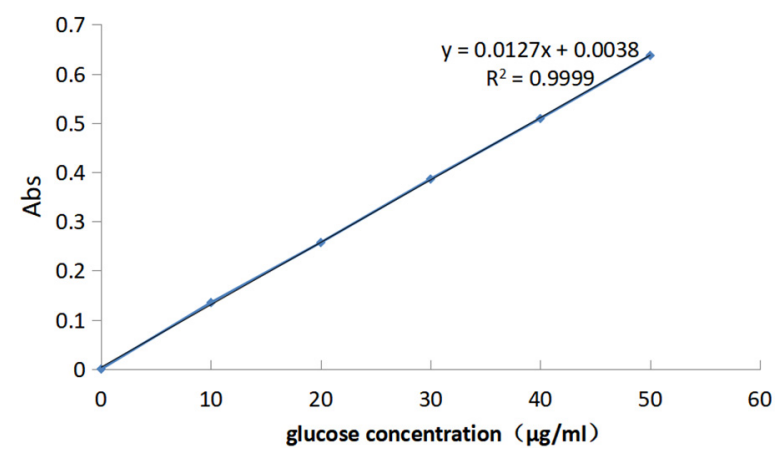

Fig.1. The glucose standard curve

\subsection{Single factor experiment}

Referring to the relevant literature[8-10], the factors of single factor experiment were determined ( shown in Table 1).

Table 1. Single factor experimental condition

\begin{tabular}{|c|c|c|c|c|}
\hline \multirow{2}{*}{$\begin{array}{c}\text { Cond } \\
\text { ition }\end{array}$} & $\begin{array}{c}\text { A } \\
\text { liquid } \\
\text {-solid } \\
\text { ratio }\end{array}$ & $\begin{array}{c}\text { B } \\
\text { extracti } \\
\text { on time }\end{array}$ & $\begin{array}{c}\text { Cers } \\
\text { extraction } \\
\text { temperature } \\
\left.{ }^{\circ} \mathrm{C}\right)\end{array}$ & $\begin{array}{c}\text { Sodium } \\
\text { hydroxide } \\
\text { concentrat } \\
\text { ion(mol/1) }\end{array}$ \\
\hline 1 & $\mathrm{X} 1$ & 5 & 80 & 0.5 \\
\hline 2 & $20: 1$ & $\mathrm{X} 2$ & 80 & 0.5 \\
\hline 3 & $20: 1$ & 5 & $\mathrm{X} 3$ & 0.5 \\
\hline 4 & $20: 1$ & 5 & 80 & $\mathrm{X} 4$ \\
\hline
\end{tabular}

\subsubsection{Sample preparation}

Millet bran was obtained by shelling millet samples (called QinZhou millet)with a rice huller and grinding them thoroughly in a mill. The millet bran was sifted through 40 meshes, then packed and collected in sealed bags and stored in a ventilated and dry place for reserve.

\subsubsection{Polysaccharide extraction}

\subsubsection{Enzymolysis process}

a. Weigh $0.5000 \pm 0.0050 \mathrm{~g}$ sample into a $50 \mathrm{ml}$ centrifugal tube, and a certain volume of water solution was added in proportion, then kept warm at $80^{\circ} \mathrm{C}$ after mixed.

b. Add $50 \mu \mathrm{L}$ heat-stable $\alpha$-amylase solution, while stirring at low speed. Place samples in water bath at $80 \pm 1^{\circ} \mathrm{C}$ and incubate for 1 hour. Remove all sample tunes from hot water bath and cool to $60^{\circ} \mathrm{C}$.

c. Add $15 \mathrm{mg}$ Papain to each sample, then inactivate enzyme in water bath at $98-100^{\circ} \mathrm{C}$ for 10 minutes after enzymolysis in water bath at $60 \pm 1^{\circ} \mathrm{C}$ for 1 hour.

d. Add $400 \mu \mathrm{L}$ glucoamylase solution, then inactivate enzyme in water bath at $98-100^{\circ} \mathrm{C}$ for 10 minutes after enzymolysis in water bath at $60 \pm 1^{\circ} \mathrm{C}$ for 1 hour.

e. Extracted the above enzymatic hydrolysate for 4 hours in $80 \pm 1^{\circ} \mathrm{C}$ water bath, then centrifugated for 15 min under $3000 \mathrm{r} / \mathrm{min}$. The supernatant was discarded and the sediment remained.

\subsubsection{Alkaline extraction process}

Add a certain volume of sodium hydroxide solution of a certain concentration to the reserved sediment, mix it well at different temperatures, take it out after a certain time in water bath, drop hydrochloric acid into the centrifugal tube, and adjust the $\mathrm{pH}$ to neutral.

After centrifuging the extract at $3000 \mathrm{r} / \mathrm{min}$ for 15 minutes, the supernatant was transferred to $250 \mathrm{ml}$ clean beaker and dripped into 3-4 times volume of 95\% ethanol slowly under continuous stirring condition. The alcohol deposit fluid was transferred to centrifuge again (3000rpm, 15 min)after resting overnight. The supernatant was discarded, and the precipitate was reserved, which was exactly the crude polysaccharides from millet bran.It was dissolved and mixed in a $100 \mathrm{ml}$ volumetric flask. The concentration of polysaccharide was determined by sulfuric acid-phenol method[11].

\subsubsection{Experimental results and analysis}

The extraction rate of polysaccharide from millet bran under each single factor experiment condition was calculated. The formula(1) for calculation was as follows:

$$
\eta=\frac{C \times V}{\mathrm{~m}} \times F \div 10000
$$

In the formula (1): $\eta$ - the extraction rate of millet bran polysaccharides, $\%$; $\mathrm{C}$-the concentration of polysaccharides in millet bran, $\mu \mathrm{g} / \mathrm{ml}$, calculated 
according to the regression equation of glucose standard curve; $\mathrm{V}$ - the total volume of sample solutions after dissolution, $\mathrm{ml} ; \mathrm{m}$ - the millet bran sample weight, $\mathrm{g}$; $\mathrm{F}$ - dilution multiple of test solution.

\subsubsection{Effects of liquid-solid ratio on extraction rate of polysaccharides}

As Fig.2 showed that the liquid-solid ratio was 10:1, 15:1, 20:1, 25:1, 30:1 respectively. The polysaccharide can not be extracted effectively with the small liquid-solid ratio, while the concentration would be diluted with a larger liquid-solid ratio. Therefore, 20:1 is the suitable liquidsolid ratio for polysaccharide extraction.

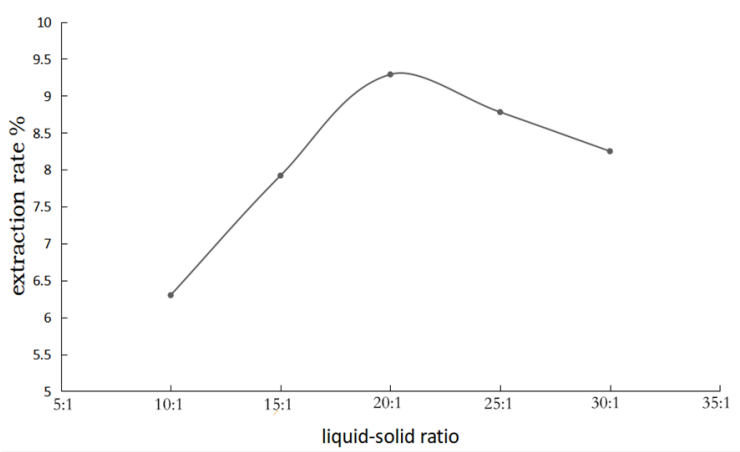

Fig.2. Effects of liquid-solid ratio on extraction rate

\subsubsection{Effects of extraction time on extraction rate of polysaccharides}

The extraction rates of polysaccharides at 2.0, 3.0, 4.0, 5.0 and $6.0 \mathrm{~h}$ were studied respectively. Fig. 3 showed the extraction rate increased rapidly with the extension of extraction time from $2.0 \mathrm{~h}$ to $5.0 \mathrm{~h}$, and reached the maximum value at $5.0 \mathrm{~h}$, then decreased slowly. This is because too long time will lead to alkali catalyzed degradation of polysaccharides under high temperature and alkaline conditions. So $5.0 \mathrm{~h}$ is more appropriate.

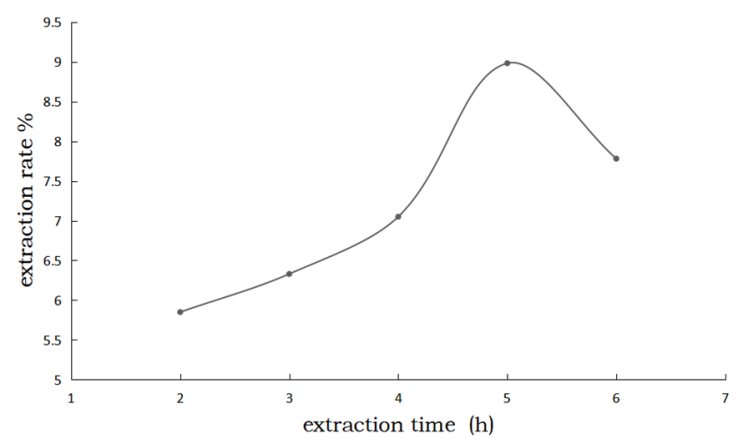

Fig.3. Effects of extraction time on extraction rate

\subsubsection{Effects of extraction temperature on extraction rate of polysaccharides}

The extraction rate of millet bran polysaccharides was investigated at $50,60,70,80$ and $90^{\circ} \mathrm{C}$. The extraction rate increased obviously with the increase of temperature in the range of $50-80^{\circ} \mathrm{C}$, and then the yield decreases at
$90{ }^{\circ} \mathrm{C}$. This is because the diffusion coefficient of polysaccharides increases at higher temperatures. However, when the temperature is too high, the degradation and denaturation of polysaccharides will increase, which will reduce the extraction rate of polysaccharides. The maximum value appeared at $80^{\circ} \mathrm{C}$.

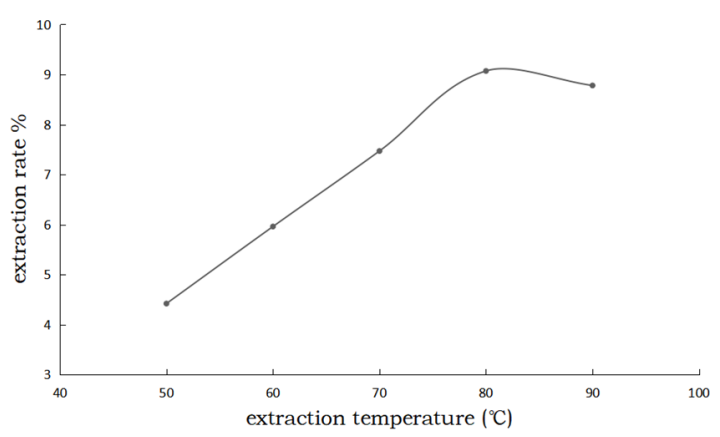

Fig.4. Effects of extraction temperature on extraction rate

\subsubsection{Effects of alkali concentration on extraction rate of polysaccharides}

The effects of different $\mathrm{NaOH}$ concentration(varied from $0.3,0.5,0.7,0.9$ to $1.1 \mathrm{~mol} / \mathrm{l}$ )on polysaccharide extraction were studied. With the increase of alkali concentration, the extraction rate increased gently, and then decreased significantly from 0.9 to $1.1 \mathrm{~mol} / \mathrm{l}$. Because alkali can contribute to removing the intermolecular interactions between cell wall polymers and promoting the dissolution of polysaccharides from cells. However, excessive alkali concentration leads to the hydrolysis of polysaccharides under alkali-catalyzed condition.Therefore, $0.7 \mathrm{~mol} / \mathrm{l}$ is a more appropriate concentration.

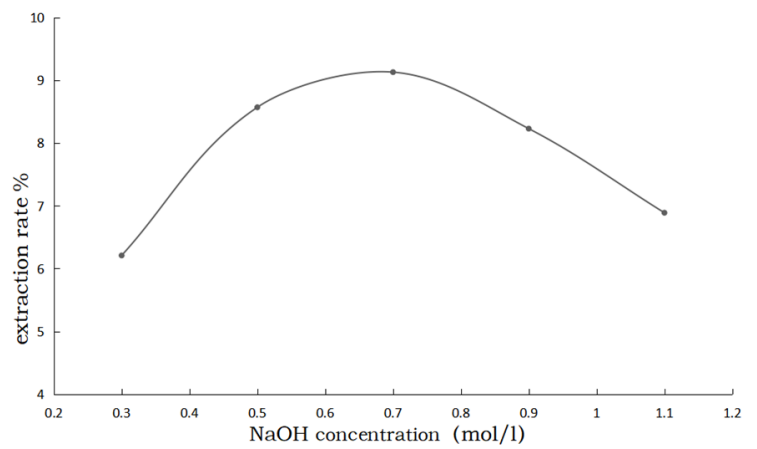

Fig.5. Effects of alkali concentration on extraction rate

\subsection{Orthogonal optimization}

According to the above experimental results, the orthogonal design experiment was carried out for four factors of liquid-solid ratio, extraction time, extraction temperature and alkali concentration at three levels. The factors and levels of orthogonal design experiment were given in Table 2. The extraction rate and range analysis of polysaccharides under different conditions were shown in Table 3, and the main effect diagram was shown in Fig. 6. 
Table 2. Orthogonal experimental factors

\begin{tabular}{|c|c|c|c|c|}
\hline Factors & $\mathrm{A}$ & $\mathrm{B}$ & $\mathrm{C}$ & $\mathrm{D}$ \\
\cline { 2 - 5 } & $\begin{array}{c}\text { Liquid } \\
\text {-solid } \\
\text { ratio }\end{array}$ & $\begin{array}{c}\text { extractio } \\
\mathrm{n} \text { time } \\
(\mathrm{h})\end{array}$ & $\begin{array}{c}\text { extraction } \\
\text { temperatu } \\
\text { re } \\
\left({ }^{\circ} \mathrm{C}\right)\end{array}$ & $\begin{array}{c}\text { Sodium } \\
\text { hydroxide } \\
\text { concentrati } \\
\text { on (mol/l) }\end{array}$ \\
\hline 1 & $15: 1$ & 4 & 70 & 0.5 \\
\hline 2 & $20: 1$ & 5 & 80 & 0.7 \\
\hline 3 & $25: 1$ & 6 & 90 & 0.9 \\
\hline
\end{tabular}

Table 3. Orthogonal experimental design scheme

\begin{tabular}{|c|c|c|c|c|c|}
\hline Table 3. Orthogonal experimental design scheme \\
\hline 1 & 1 & 1 & 1 & 1 & 5.21 \\
\hline 2 & 1 & 2 & 2 & 2 & 11.48 \\
\hline 3 & 1 & 3 & 3 & 3 & 8.54 \\
\hline 4 & 2 & 1 & 2 & 3 & 6.44 \\
\hline 5 & 2 & 2 & 3 & 1 & 10.12 \\
\hline 6 & 2 & 3 & 1 & 2 & 7.38 \\
\hline 7 & 3 & 1 & 3 & 2 & 10.8 \\
\hline 8 & 3 & 2 & 1 & 3 & 8.57 \\
\hline 9 & 3 & 3 & 2 & 1 & 8.87 \\
\hline K1 & 8.02 & 7.48 & 7.05 & 8.07 & \\
\hline K2 & 7.98 & 10.05 & 8.93 & 9.88 & \\
\hline K3 & 9.41 & 8.26 & 9.82 & 7.85 & \\
\hline R & 1.43 & 2.57 & 2.77 & 2.03 & \\
\hline
\end{tabular}

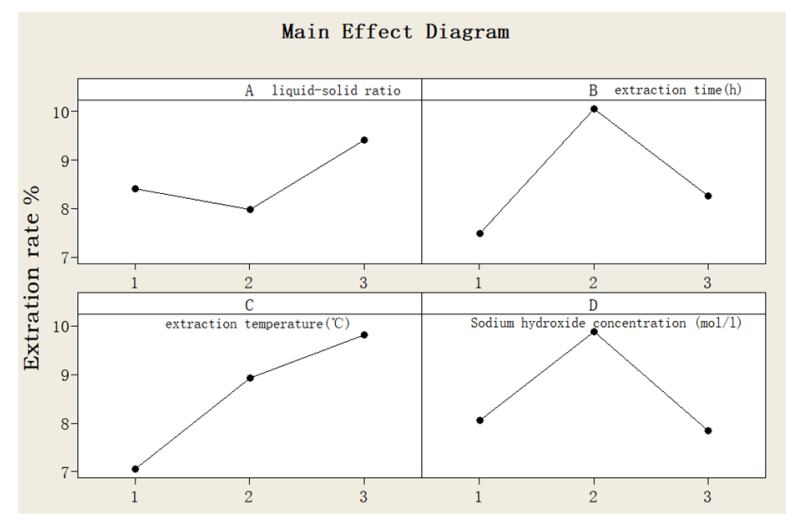

Fig. 6. Main effect diagram of extraction rate of millet bran polysaccharides

By comparing the extreme difference value $(\mathrm{R})$ of each factor in Table 3 and the shape of Fig.6, we can learn that the order of factors affecting polysaccharide extraction is: extraction temperature (C) $>$ extraction time (B) $>$ alkali concentration (D) > liquid-solid ratio (A).

\section{Conclusion}

In conclusion, the optimum extraction parameters for alkali extraction of millet bran polysaccharides were as follows: $15: 1$ liquid-solid ratio, $5 \mathrm{~h}$ extraction time, $80^{\circ} \mathrm{C}$ extraction temperature, $0.7 \mathrm{~mol} / 1$ sodium hydroxide concentration. Under these conditions, the extraction rate of polysaccharides was $11.46 \%, 11.66 \%$ and $11.25 \%$ respectively after repeated experiments for verification. The average extraction rate of polysaccharide was $11.46 \%$ and RSD was $1.79 \%$. The results showed that the extraction process was stable and reliable, which could provide some reference for the further research of millet bran polysaccharides.

\section{References}

1. Haibin Wang, Jianxin Xia. Nutritional components and product research development of millet[J]. Grain Science and Technology and Economy, 2010, 35(4): 36.

2. Yueyuan Xue, Li Peng, Qinbao Lin. Research Progress on Chemical Constituents and Physical Properties of Millet[J]. Journal of the Chinese Cereals and Oils Association, 2008, 23(3): 199-203.

3. Beiyu Liu, Hongyan Zheng, Zhong Geng, etal. Determination of dietary fiber composition and physicochemical properties of millet bran [J]. Journal of the Chinese Cereals and Oils Association, 2011, 26 (10): 30.

4. Schneeman, B.O. Dietary fiber and gastrointestinal function. In: McCleary, B.V., and Prosky, L. Eds. Advanced Dietary Fiber Technology. Ames, IA: Blackwell Sciences, Ltd., 2001, 168-176.

5. M“alkki, A. 2001. Physical properties of dietary fiber as keys to physiological functions, Cereal Foods World, 46:196-199.

6. Hanyu Liang, Wang Jian, Xiaowen Ding, etal. Research progress on the hypolipidemic effect of guar gum[J].Food Industry Science and Technology, 2013 (11): 388-389.

7. LIU Bo, Qinlu LIN. Research Progress on Physiological Functions of Oat Glucan [J]. Grain and Oil, 2016, 29 (2): 1-3.

8. Haixia $\mathrm{Wu}$, Guogang Ma, Yifeng Lin, etal. Optimization of extraction technology of millet bran polysaccharide by response surface methodology [J].Journal of Yuncheng University, 2016, 34 (3): 52-54.

9. Chaozhu Li, Yanhui Chen, Dengzheng Wang, etal. Optimization of extraction technology of rice bran polysaccharides [J]. Food Industry,2015,36(4) :2325.

10. Li Li Wang, Zhang Li. Orthogonal optimization of ultrasonic assisted extraction of rice bran 
polysaccharides [J]. Guangdong Feed, 2014, 23 (9): 37-39.

11. Aishi Zhu, JinnaYe, Feina Yan. Uniform design optimization of millet polysaccharide extraction process [J].Journal of Zhejiang Institute of Science and Technology, 2013, 25(1): 27-32. 